\title{
Predicting Solar and Wind Based Computation Using Square Difference Labelling Technique
}

\section{P. Jagadeeswari}

\begin{abstract}
In this paper we have shown that the graph $D_{n}$, $C\left(L_{n}\right), T(n, m), K_{1}+K_{1, n}$, balloon of the triangular snake, $\operatorname{DHF}(n)$, bull graph $\left(C_{3}\right)$, Duplication of the pendant vertex by the edge of bull graph $\left(C_{3}\right)$ and one point union of $\left(\text { bull }\left(C_{3}\right)\right)^{k}$ is a square difference graph.

Keywords: Square Difference, Circular Ladder, Balloon Graph, Bull Graph

AMS classification: $05 C 78$
\end{abstract}

\section{INTRODUCTION}

In a thorough manner, we utilize simple, undirected and finite graph and we follow [2,3,6] square difference labelingare studied in [4,8]. In [7] Sankari proved umbrella and tadpole graph for odd-even graceful labelling. Jayasekaran investigated umbrella, dumb bell and circular ladder for one edge trimagic labelling. In this work, we prove some various graphs for Square Difference Labeling.

We present some definitions, which are helpful for our work.

\section{Definition 1.1}

If a graph ' $G$ ' admits a bijective function $\mathrm{g}: \mathrm{V} \rightarrow\{0,1,2$, .....p-1\} such that the induced function $g^{*}: E(G) \rightarrow N$ given by $\mathrm{g}^{*}(\mathrm{x}, \mathrm{y})=\left|[\mathrm{g}(\mathrm{x})]^{2}-[\mathrm{g}(\mathrm{y})]^{2}\right|$ are all distinct , $\forall x y \in E(G)$ is called Square Difference graph.

\section{Definition 1.2}

The Dumb Bell graph $\mathrm{Db}_{\mathrm{m}}$ is obtained by two disconnected cycles $c_{m}$ joined by an edge.

Definition 1.3

A Circular Ladder $\mathrm{C}\left(\mathrm{L}_{\mathrm{n}}\right)$ in the union of an outer cycle $c_{0}: u_{l}$ $u_{2} u_{3} \ldots u_{n} u_{1}$ and an inner cycle $c_{1}: v_{1} v_{2} v_{3} \ldots . v_{n} v_{l}$ with additional edge $u_{j} v_{j}, \mathrm{i}=1,2, \ldots . n$ called spokes.

\section{Definition 1.4}

A tadpole $T(n, m)$ in the graph obtained by attaching a path $\mathrm{P}_{\mathrm{m}}$ to cycle $\mathrm{C}_{\mathrm{n}}$.

\section{MAIN RESULTS}

Theorem 2.1.

$\mathrm{Db}_{\mathrm{m}}$ admits Square difference labeling. Proof:

Let $\mathrm{G}=\mathrm{Db} b_{\mathrm{m}}$ be the dumb bell graph with vertices $u_{l}$, $u_{2} \ldots u_{m} \& v_{l}, v_{2} \ldots v_{m}$ and the edges $u_{i} u_{i+1}, v_{i} v_{i+1}, u_{l} v_{l}, u_{m} u_{l}$ and $v_{m} v_{l}$ for $\mathrm{i}=1,2 \ldots m-1$.

Clearly, $|\mathrm{V}(\mathrm{G})|=2 m$ and $|\mathrm{E}(\mathrm{G})|=2 m+1$.

Now, define the vertex function $f: 0,1 \ldots . .2 m$ as

$$
\begin{aligned}
& f\left(u_{i}\right)=2(i-1) \\
& f\left(v_{i}\right)=2 i-1 \text { for } \mathrm{i}=1,2 \ldots \mathrm{m}
\end{aligned}
$$

And the induced function $f^{*}$ be

$$
\begin{aligned}
& f^{*}\left(u_{i} u_{i+1}\right)=8 i-4 \\
& f^{*}\left(\mathrm{v}_{\mathrm{i}} \mathrm{v}_{\mathrm{i}+1}\right)=8 i \quad \text { for } 1 \leq i \leq m-1 \\
& f^{*}\left(\mathrm{u}_{1} \mathrm{v}_{1}\right)=1 \\
& f^{*}\left(u_{m} u_{1}\right)=\left[f\left(u_{m}\right)\right]^{2} \\
& f^{*}\left(v_{m} v_{l}\right)=\left[f\left(v_{m}\right)\right]^{2}-1
\end{aligned}
$$

Hence, all the edge labeling are distinct.

Therefore, $\mathrm{Db}_{m}$ admits Square difference labeling

\section{Example 2.1:}

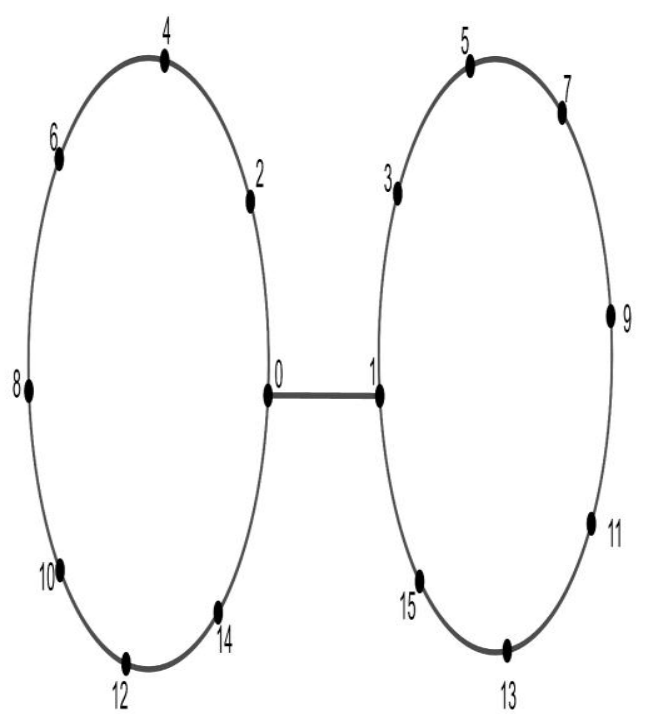

Fig 1. SDL of $\mathrm{DB}_{8}$

Theorem 2.2.

The Circular Ladder $\mathrm{C}\left(\mathrm{L}_{\mathrm{n}}\right)$ is $\mathrm{SDG}$.

Proof:

Consider the circular ladder graph with the vertex set $u_{j}$ and $v_{j}$ for $j=1,2 \ldots n$ and the edge set $\mathrm{E}=\left\{u_{i} u_{i+1}, v_{i} v_{i+1}, u_{l} v_{l}, u_{n}\right.$ $u_{l}$ and $\left.v_{n} v_{l}, u_{j} v_{j}\right\}, j=1,2 \ldots n-1$.

Obviously, $\left|\mathrm{V}\left[\mathrm{C}\left(\mathrm{L}_{\mathrm{n}}\right)\right]\right|=2 n$ and $\left|E\left[C\left(L_{n}\right)\right]\right|=3 n$

Now, define the vertex function $f \&$ edge function $f^{*}$ as

$$
\begin{aligned}
& f\left(u_{j}\right)=2(j-1) \\
& f\left(v_{j}\right)=2 j-1 \text { for } j=1,2 \ldots n \\
& \text { and }
\end{aligned}
$$




$$
\begin{aligned}
& f^{*}\left(u_{j} u_{j+1}\right)=8 j-4 \equiv 0(\bmod 4) \\
& f^{*}\left(v_{j} v_{j+1}\right)=8 i=0(\bmod 8) \\
& f^{*}\left(u_{n} u_{l}\right)=\left[f\left(u_{n}\right)\right]^{2} \\
& f^{*}\left(v_{m} v_{l}\right)=\left[f\left(v_{n}\right)\right]^{2}-1 \\
& f^{*}\left(u_{j} v_{j}\right)=4 j-3
\end{aligned}
$$

here, $f^{*}\left(u_{j} u_{j+1}\right)<f^{*}\left(v_{j} v_{j+1}\right), \mathrm{j}=1,2 \ldots \ldots . n-1$. Thus, the entire $3 \mathrm{n}$ edges labels are distinct. Hence the theorem.

\section{Example 2.2:}

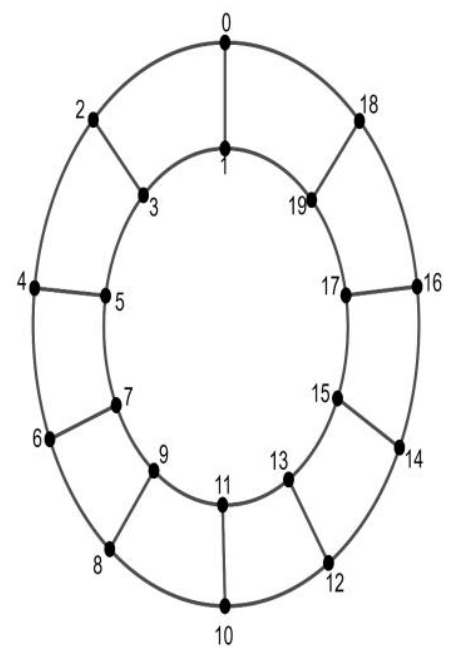

Fig 2. $\mathbf{C}\left(\mathrm{L}_{10}\right)$

\section{Theorem 2.3:}

The Bull $\left(\mathrm{C}_{3}\right)$ graph is Square difference graph. Proof:

Define the bull graph $\left(\mathrm{C}_{3}\right)$ with 5 vertices and 5 edges.

Let the bijective function $f: 0,1,2 \ldots 4$ as

$$
f\left(v_{i}\right)=i-1 \text { for } 1 \leq i \leq 5
$$

For the above labeling, we receive the edge label as:

$$
\begin{aligned}
& f^{*}\left(v_{j} v_{j+l}\right)=2 i-1 \\
& f^{*}\left(v_{2} v_{4}\right)=8
\end{aligned}
$$

Thus, the induced function $f^{*}\left(e_{i}\right) \neq f^{*}\left(e_{j}\right) \forall e_{i}, e_{j} \in$ $\mathrm{E}\left(\mathrm{C}_{3}\right)$. Hence the bull $\left(\mathrm{C}_{3}\right)$ graph is Square difference graph.

\section{Example 2.3:}

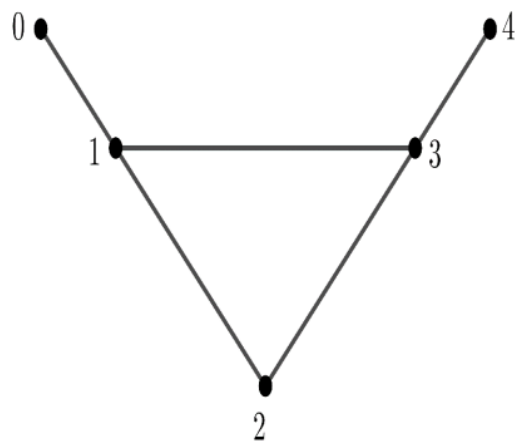

Fig 3. Bull $\left(\mathbf{C}_{3}\right)$

\section{Theorem 2.4:}

Duplication of the pendant vertex by the edge of bull graph $\left(\mathrm{C}_{3}\right)$ in SDG.

Proof:

Consider the graph $G$ with
$V(G)=\left\{x_{j}, x_{1}^{\prime}, x_{1}^{\prime \prime}, x_{5}^{\prime}, x_{5}^{\prime \prime}\right\} \quad 1 \leq j \leq 5$ and

$E(G)=\left\{x_{j} x_{j+1}, x_{1}^{\prime} x_{1}^{\prime \prime}, x_{1} x_{1}^{\prime}, x_{1}^{\prime} x_{1}^{\prime \prime}, x_{5} x_{5}^{\prime}, x_{5}^{\prime} x_{5}{ }^{\prime \prime}\right\} \quad 1 \leq j \leq 4$

Clearly, $|V(G)|=9 \&|E(G)|=11$.

Define the bijective function $f: \mathrm{V}(\mathrm{G}) \rightarrow\{0,1 \ldots 8\}$ as

$$
\begin{aligned}
& f\left(x_{j}\right)=j-1, \quad 1 \leq j \leq 5 \\
& f\left(x_{1}^{\prime}\right)=f\left(x_{5}\right)+1 \\
& f\left(x_{1}{ }^{\prime \prime}\right)=f\left(x_{5}\right)+3 \\
& f\left(x_{5}^{\prime}\right)=6 \\
& f\left(x_{5}{ }^{\prime \prime}\right)=8
\end{aligned}
$$

and $f^{*}$ yields the edge labeling as follows:

$$
\begin{aligned}
& f^{*}\left(x_{j} x_{j+1}\right)=2 j-1, \quad 1 \leq j \leq 4 \\
& f^{*}\left(x_{2} x_{4}\right)=8 \\
& f^{*}\left(x_{1}^{\prime}, x_{1}\right)=24 \\
& f^{*}\left(x_{1} x_{1}\right)=25 \\
& f^{*}\left(x_{1}^{\prime}, x_{1}\right)=49 \\
& f^{*}\left(x_{5} x_{5}^{\prime}\right)=20 \\
& f^{*}\left(x_{5}^{\prime}, x_{5}^{\prime \prime}\right)=48
\end{aligned}
$$

Thus, the labeling of edges of $G$ are distinct and hence the theorem.

\section{Example 2.4:}

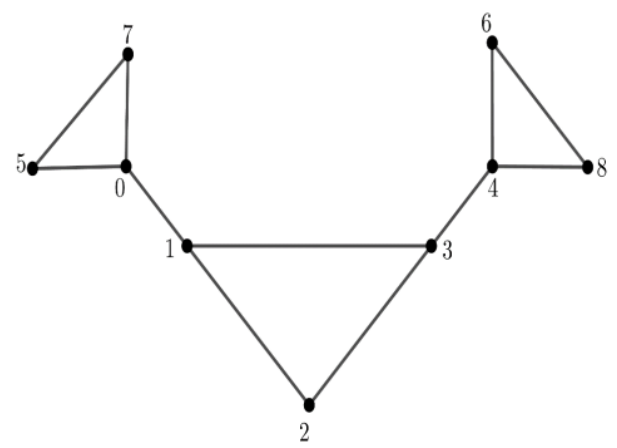

Fig 4. SDL for duplication of pendant vertex of bull $\left(C_{3}\right)$

\section{Theorem 2.5:}

The one-point union of ' $r$ ' copies of bull graph $\left(\mathrm{C}_{3}\right)$ admits SDL.

\section{Proof:}

Let the vertex set and edge set of the one-point union of ' $r$ ' copies of $\left[\right.$ bull $\left.\left(\mathrm{C}_{3}\right)\right]$ are

$V=\left\{v_{i}^{(k)}, w / 1 \leq i \leq 4,1 \leq k \leq r\right\}$ and

$\mathrm{E}=\left\{v_{i}{ }^{(k)} v_{i+1}{ }^{(k)}, \mathrm{w} \mathrm{v}_{2}{ }^{(\mathrm{k})}, \mathrm{w} \mathrm{v}_{3}{ }^{(\mathrm{k})}, / 1 \leq i \leq 4,1 \leq k \leq r\right\}$

Clearly, the number of vertices and edges are $4 r+1$ and $5 r$ respectively,

Consider $f: V\left[\operatorname{bull}\left(\mathrm{C}_{3}\right)\right]^{\mathrm{k}} \rightarrow\{0,1 \ldots .4 r\}$ as

$$
\begin{aligned}
& f(w)=0 \\
& f\left(v_{i}^{(k)}\right)=i+4(k-1)
\end{aligned}
$$

Clearly, $f$ is bijective and induces $f^{*}$ on $E\left[\text { bull }\left(\mathrm{C}_{3}\right)\right]^{\mathrm{k}}$ such that $f(u v)=\left|(f(u))^{2}-(f(v))^{2}\right|, \forall u v \in E$ and receive edge labels as,

$$
\begin{aligned}
& f^{*}\left(v i^{(k)} v_{i+1}{ }^{(k)}\right)=(2 i+1)+8(k-1) \\
& f^{*}\left(w v_{2}{ }^{(k)}\right)=(4 k-2)^{2} \\
& f^{*}\left(w v_{3}{ }^{(k)}\right)=(4 k-
\end{aligned}
$$

$1)^{2} \quad 1 \leq k \leq r$ 
Thus, the edge in E have distinct labels. Therefore, the theorem is verified.

\section{Example 2.5}

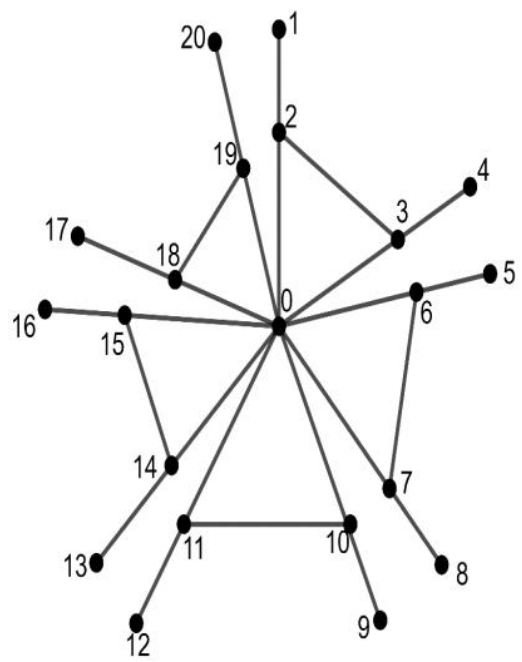

Fig 5. SDG of $\left(C_{3}\right)^{5}$

\section{Theorem 2.6:}

The Tadpole graph $\mathrm{T}(n, m)$ is SDG.

\section{Proof:}

Consider the tadpole graph with the vertices $v_{1}, v_{2}, \ldots n+m-$ 1 and the edges $v_{i} v_{i+1}, v_{n+m-1} v_{m}, i=1,2 \ldots n+m-2$.

Clearly the cardinality of vertex set and edge set are $n+m-$ 1 .

Now, define the vertex values function ' $G$ ' as

$$
g\left(v_{i}\right)=i-1 \quad 1 \leq i \leq n+m-1
$$

And the induced edge function $g$ * for the above labeling pattern, we get,

$$
\begin{aligned}
& g{ }^{*}\left(v_{i} v_{i+1}\right)=2 i-1,1 \leq i \leq n+m-2 \\
& g{ }^{*}\left(v_{n+m-1} v_{m}\right)=\left[g\left(v_{n+m-1}\right)\right]^{2}-\left[g\left(v_{m}\right)\right]^{2}
\end{aligned}
$$

Hence $g^{*}\left(\mathrm{e}_{\mathrm{i}}\right) \neq g^{*}\left(\mathrm{e}_{\mathrm{j}}\right) \forall e_{i}, e_{j} \in E(G)$ i.e., all the edge labeling are distinct and strictly increasing.

Thus, $T(n, m)$ is SDG.

\section{Example 2.6:}

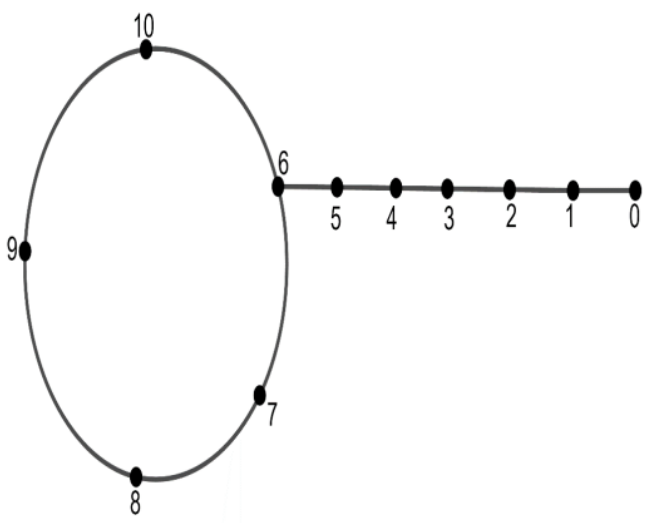

Fig 6. SDL for $T(5,7)$

\section{Theorem 2.7:}

The graph $\mathrm{K}_{1}+\mathrm{K}_{1, \mathrm{n}}$ admits SDL.

Proof:

Let $G=\mathrm{K}_{1}+\mathrm{K}_{1, \mathrm{n}}$ with $|\mathrm{V}(\mathrm{G})|=n+2$ and $|\mathrm{E}(\mathrm{G})|=2 n+1$.

The vertex set and edge set are defined as

$\mathrm{V}(\mathrm{G})=\left\{u, w, x_{i} / 1 \leq i \leq n\right\} \&$

$\mathrm{E}(\mathrm{G})=\left\{u x_{i}, u w, w x_{i} / 1 \leq i \leq n-1\right\}$

Define a mapping $f: \mathrm{V}\left(\mathrm{K}_{1}+\mathrm{K}_{1, \mathrm{n}}\right) \rightarrow\{0,1,2 \ldots n-1\}$ as

$$
\begin{aligned}
& f\left(x_{i}\right)=i+1 \\
& f(u)=0 \\
& f(w)=1
\end{aligned}
$$

Then ' $f$ ' induces an edge mapping $f$ ' receives edge labeling as,

$$
\begin{aligned}
& f^{*}\left(u x_{i}\right)=[i+1]^{2} \\
& f^{*}(u w)=1 \\
& f^{*}\left(w x_{i}\right)=[i+1]^{2}-1
\end{aligned}
$$

Thus, the entire $2 n+1$ edge receives distinct labeling. Hence, the graph $\mathrm{K}_{1}+\mathrm{K}_{1, \mathrm{n}}$ is $\mathrm{SDG}$.

\section{Example 2.7.}

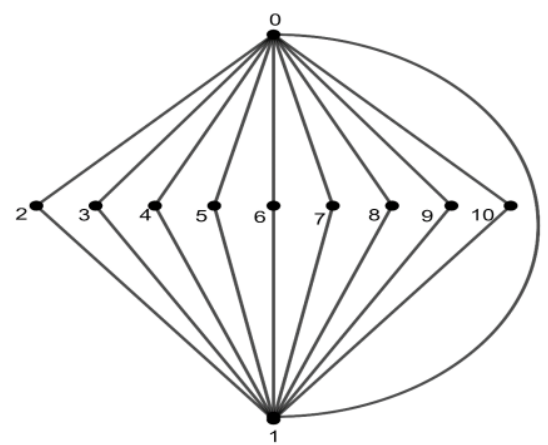

Fig 7. SDL for $K_{1}+K_{1,9}$

\section{Theorem 2.8.}

The balloon of the triangular snake graph $T_{n}\left(C_{m}\right)$ is square difference graph.

\section{Proof:}

Let $v_{1}, v_{2} \ldots v_{n}$ and $w_{1}, w_{2} \ldots w_{n-1}$ be the vertices of $T_{n}$ and $v_{n+1}$, $v_{n+2} \ldots v_{n+m-1}$ be the vertices of $C_{m}$.

Obviously,

$$
|\mathrm{V}(\mathrm{G})|=2 n+m-2 \text { and }
$$

$$
|\mathrm{E}(\mathrm{G})|=m+3 n-3
$$

Let ' $f$ ' be the bijective function from $f: \mathrm{V} \rightarrow\{0,1,2 \ldots .2 n+m-$ 1\} as

$$
\begin{aligned}
& f\left(v_{j}\right)=2(j-1) 1 \leq j \leq n \\
& f\left(w_{j}\right)=2 j-1 \quad 1 \leq j \leq n-1 \\
& f\left(v_{n+j}\right)=f\left(v_{n}\right)+j \quad 1 \leq j \leq n+\mathrm{m}-1
\end{aligned}
$$

For the above vertex labeling, we receive the edge label as.

$$
\begin{gathered}
f^{*}\left(\mathrm{v}_{\mathrm{j}} \mathrm{v}_{\mathrm{j}+1}\right)=8 j-4 \equiv 0(\bmod 4), 1 \leq j \leq n-1 \\
f^{*}\left(v_{n+j} v_{n+j+1}\right)=4 n+2 j-3,0 \leq j \leq m-2 \\
f^{*}\left(v_{j} w_{j}\right)=4 j-3 \\
f^{*}\left(w_{j} v_{j+1}\right)=4 j-1 \quad 1 \leq j \leq n-1
\end{gathered}
$$

Hence, $f^{*}\left(\mathrm{e}_{\mathrm{i}}\right) \neq f^{*}\left(\mathrm{e}_{\mathrm{j}}\right), \forall e_{i}, e_{j} \in \mathrm{E}(\mathrm{G})$, Thus, all the edges receive distinct labeling. Therefore, the theorem is verified. 
Example: 2.8.

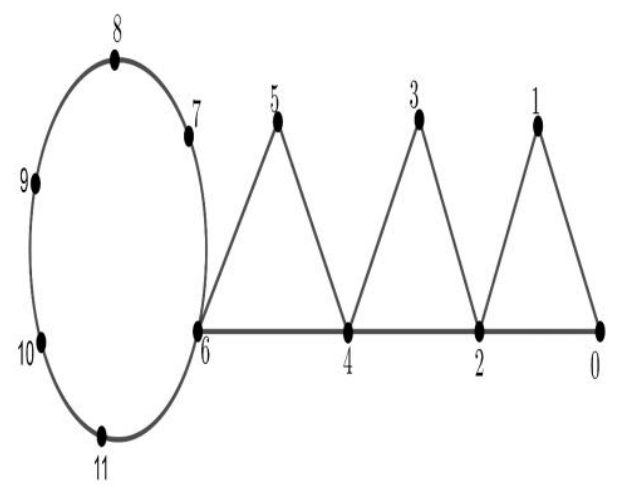

Fig 8. $T_{4}\left(C_{6}\right)$

\section{Theorem 2.9:}

$\operatorname{DHF}(n)$ admits square difference labeling.

\section{Proof:}

Let, the double headed circular fan $\operatorname{DHF}(\mathrm{n})$ be the cycle $v_{l}$, $v_{2} \ldots v_{n} v_{l}$ with the additional edges $v_{i} u, i=1,2 \ldots \ldots n-3$ and $v_{i} v, i=n-2, n-1, n$

Clearly,

$$
\begin{aligned}
& |\mathrm{V}(\mathrm{DHF}(n)]|=n+2 \text { and } \\
& |\mathrm{E}(\operatorname{DHF}(n)]|=2 n
\end{aligned}
$$

Define, the vertex valued function $f$ as follows:

$$
\begin{aligned}
& f\left(v_{j}\right)=j-1 \quad 1 \leq j \leq n \\
& f(w)=9 \\
& f(u)=n+1
\end{aligned}
$$

For, the above defined labeling, we receive $f^{*}$ as follows:

$$
\begin{aligned}
& f^{*}\left(v_{j} v_{j+1}\right)=2 j-1,1 \leq j \leq n \\
& f^{*}\left(u v_{j}\right)=(n+1)^{2}-(j+1)^{2}, 1 \leq j \leq n-3 \\
& \quad f^{*}\left(w v_{j}\right)=\left|n^{2}-f\left(v_{j}\right)^{2}\right| j=n-2, n-1, n .
\end{aligned}
$$

Thus, all the edge labels are different. Hence, the theorem is verified.

\section{Example 2.9.}

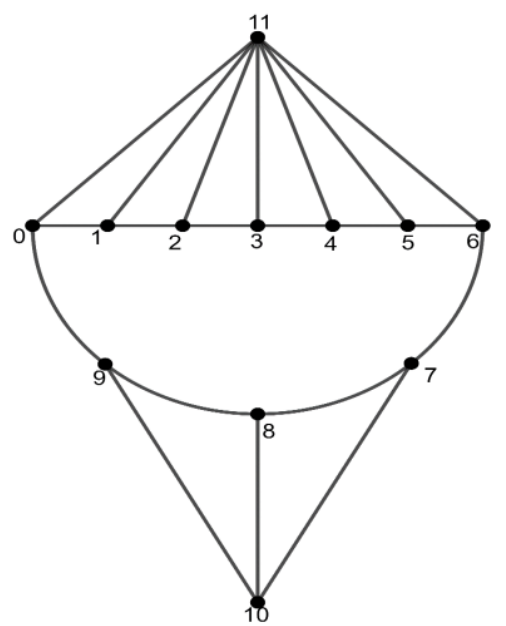

Fig 9. DHF(10)

\section{CONCLUSION}

In this work, we proved that some cycle related graphs admit Square difference labeling.

\section{REFERENCES}

1. J. Arthy, K. Manimegalai, K. Ramanathan "Cycle and Path Related Graphs on L-cordial Labeling", International Journal of Innovative Science and Research Technology, vol (4)6, 2019, ISSN. No: 2456 2165.

2. Frank Harary "Graph Theory", Narosa Publishing House, 2001

3. Gallian J.A “A Dynamic Survey of Graph Labeling”, The Electronic Journal of Combinatorics, \#DS6, 2017.

4. P. Jagadeeswari, K. Manimekalai, K. Bhuvaneswari "Square Difference Labeling of Cycle, Path \& Tree related Graph", Advancement in Engineering, Science \& Technology, J. Mech. Cont.\& Math. Sci., Special Issue, No.-2, August (2019) pp 627-631

5. C. Jayasekaran and J. Little Flower "One Edge Trimagic Labeling of Umbrella, Dumb Bell and Circular Ladder Graphs”, Annals of Pure and Applied Mathematics, vol.13 No. 1, 2017, 73 - 87.

6. Rosa A “On Certain Valuation of Graph Theory of Graph", (Rome, July 1966), Golden \& Breach .M and Paris (1967), 349 - 355.

7. G. Sankari, S. Lawanya "Odd - Even Graceful Labeling of Umbrella and Tadpole Graphs", International Journal of Pure and Applied Mathematics, vol (114), 6, 2017, 139 - 143.

8. Shiama. J "Square Difference Labeling for Certain Graph", International Journal of Computer Applications (0975 - 08887), 44 (4), 2012.

9. Sunoj. B.S, Mathew Varkey "A Note on Square Sum Difference Product Prime Labeling", International Journal of. Advance Research in Science and Engineering, 6 (11), 2017

\section{AUTHORS PROFILE}

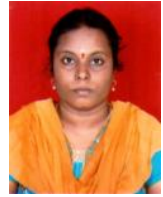

P. Jagadeeswari is an Assistant Professor, Department of Science and Humanities, BIHER, Chennai. She is currently working on Graph labeling. She published 7 papers in international journal. 